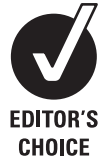

Department of Health Sciences, University of Leicester, Leicester, UK ${ }^{2}$ INSERM, UMR S149,

Epidemiological Research Unit on Perinatal and Women's Health, Paris, France;

${ }^{3}$ Department of Neonatology, Royal Victoria Infirmary, Newcastle, UK; ${ }^{4}$ Department of Obstetrics and Department of Paediatrics, Hvidovre University Hospital, Denmark: ${ }^{5}$ Department of Paediatrics, University Medical Centre Children's Hospital, Nijmegen, the Netherlands; ${ }^{6}$ Study Centre for Perinatal Epidemiology, Brussels, Belgium; 7 Institute of Quality

Assurance, Eschborn, Germany

Correspondence to:

Elizabeth S Draper, Department of Health Sciences, University of Leicester, 22-28, Princess Road West, Leicester LE1 6TP, UK; msn@leicester.ac.uk

Accepted 9 August 2008 Published Online First

19 September 2008

\title{
Investigating the variations in survival rates for very preterm infants in 10 European regions: the MOSAIC birth cohort
}

\author{
E S Draper, ${ }^{1}$ J Zeitlin, ${ }^{2}$ A C Fenton, ${ }^{3}$ T Weber, ${ }^{4}$ J Gerrits, ${ }^{5}$ G Martens, ${ }^{6}$ B Misselwitz, \\ $\mathrm{G}$ Breart, ${ }^{2}$ on behalf of the MOSAIC research group
}

\section{ABSTRACT}

Objective: To investigate the variation in the survival rate and the mortality rates for very preterm infants across Europe.

Design: A prospective birth cohort of very preterm infants for 10 geographically defined European regions during 2003, followed to discharge home from hospital.

Participants: All deliveries from $22+0$ to $31+6$ weeks' gestation.

Main outcome measure: All outcomes of pregnancy by gestational age group, including termination of pregnancy for congenital anomalies and other reasons, antepartum stillbirth, intrapartum stillbirth, labour ward death, death after admission to a neonatal intensive care unit (NICU) and survival to discharge.

Results: Overall the proportion of this very preterm cohort who survived to discharge from neonatal care was $89.5 \%$, varying from $93.2 \%$ to $74.8 \%$ across the regions. Less than $2 \%$ of infants $<24$ weeks' gestation and approximately half of the infants from 24 to 27 weeks' gestation survived to discharge home from the NICU. However large variations were seen in the timing of the deaths by region. Among all fetuses alive at onset of labour of 24-27 weeks' gestation, between $84.0 \%$ and $98.9 \%$ were born alive and between $64.6 \%$ and $97.8 \%$ were admitted to the NICU. For babies $<24$ weeks' gestation, between $0 \%$ and $79.6 \%$ of babies alive at onset of labour were admitted to neonatal intensive care.

Conclusions: There are wide variations in the survival rates to discharge from neonatal intensive care for very preterm deliveries and in the timing of death across the MOSAIC regions. In order to directly compare international statistics for mortality in very preterm infants, data collection needs to be standardised. We believe that the standard point of comparison should be using all those infants alive at the onset of labour as the denominator for comparisons of mortality rates for very preterm infants analysing the cohort by gestational age band.

Although the validity of direct comparisons of perinatal and neonatal mortality rates and their contributions to overall survival has been questioned, these figures are still routinely produced and attract often sensational media headlines. The problems associated with the collection of these data in terms of differences in definitions, registration and delivery policies (which may reflect differences in ethical attitude), have been highlighted in many publications. ${ }^{1-5}$ These limitations may mask real variations in these mortality rates which require investigation and explanation at a regional or national level.

\section{What is already known on this topic}

- Wide variations are seen in the survival of very preterm infants across Europe.

- Reporting, birth registration and policy differences contribute to published mortality rates and limit their usefulness.

\section{What this study adds}

- A standardised approach to the collection and presentation of international perinatal and infant mortality rates.

- An insight into the real variations in the outcomes of very preterm infants across Europe.

In addition, very preterm deliveries of less than 32 weeks' gestational age account for a large proportion of this mortality and very preterm delivery rates vary widely between countries. ${ }^{67}$ Over recent years technological advances have been made in neonatal intensive care in developed countries which have led to a steady reduction in perinatal and neonatal mortality rates. As a result the overall impact of very preterm births on such rates has increased. Therefore, while very preterm births of less than 32 weeks' gestation only constitute between one and two per cent of all births, they account for at least one-third of perinatal deaths.

The Models of OrganiSing Access to Intensive Care for very preterm births (MOSAIC) study aimed to standardise the data collection for very preterm infants, across 10 regions in Europe, for the total cohort of infants of $22+0$ to $31+$ 6 weeks' gestation irrespective of their outcome by minimising definitional, ascertainment and viability issues. This allowed for a more appropriate direct comparison across countries, facilitating an investigation of true differences in mortality and survival rates.

\section{METHODS}

The MOSAIC study included all outcomes of pregnancy of very preterm infants defined as $22+0$ weeks to $31+6$ weeks' gestation. Ten European regions were included. These have been 
Outcomes of pregnancy (\%) by region, models of organising access to intensive care cohort 22-31 weeks' gestation

\begin{tabular}{|c|c|c|c|c|c|c|c|c|c|c|}
\hline \multicolumn{2}{|c|}{ Country, region } & \multirow{2}{*}{$\begin{array}{r}\text { Total } \\
793\end{array}$} & \multirow{2}{*}{$\begin{array}{l}\begin{array}{l}\text { TOP } \\
\text { congenital } \\
\text { anomaly }\end{array} \\
4.2\end{array}$} & \multirow{2}{*}{$\begin{array}{c}\text { TOP other } \\
2.1\end{array}$} & \multirow{2}{*}{$\begin{array}{c}\begin{array}{c}\text { Antepartum } \\
\text { stillbirth }\end{array} \\
17.7\end{array}$} & \multirow{2}{*}{$\begin{array}{l}\begin{array}{l}\text { SB- } \\
\text { unknown } \\
\text { timing }\end{array} \\
0.0\end{array}$} & \multirow{2}{*}{$\begin{array}{c}\begin{array}{c}\text { Intrapartum } \\
\text { stillbirths }\end{array} \\
2.8\end{array}$} & \multirow{2}{*}{$\begin{array}{c}\begin{array}{l}\text { Labour } \\
\text { ward } \\
\text { deaths }\end{array} \\
4.3\end{array}$} & \multirow{2}{*}{$\begin{array}{c}\begin{array}{l}\text { Neonatal } \\
\text { unit deaths }\end{array} \\
10.6\end{array}$} & \multirow{2}{*}{$\begin{array}{c}\begin{array}{l}\text { Discharged } \\
\text { alive }\end{array} \\
58.4\end{array}$} \\
\hline $\mathrm{BE}$ & Flanders & & & & & & & & & \\
\hline DK & Eastern & 391 & 2.1 & 0.5 & 1.8 & 9.2 & 1.8 & 2.1 & 9.0 & 73.7 \\
\hline FR & Ile-de-France & 1532 & 17.6 & 3.9 & 12.9 & 1.8 & 4.8 & 4.2 & 6.8 & 47.9 \\
\hline IT & Lazio & 670 & 14.6 & 0.5 & 11.5 & 2.7 & 2.5 & 1.5 & 12.8 & 53.9 \\
\hline PO & Northern & 408 & 9.1 & 0.5 & 12.5 & 3.7 & 3.2 & 1.2 & 13.7 & 56.1 \\
\hline UK & Northern & 549 & 4.9 & 0.9 & 12.2 & 4.7 & 2.0 & 1.1 & 9.5 & 64.7 \\
\hline UK & Trent & 1000 & 4.9 & 0.2 & 13.8 & 0.6 & 3.3 & 2.0 & 10.2 & 65.0 \\
\hline \multirow[t]{2}{*}{ All } & Regions & 7222 & 586 & 103 & 923 & 193 & 213 & 220 & 759 & 4225 \\
\hline & & $100.0 \%$ & $8.1 \%$ & $1.4 \%$ & $12.8 \%$ & $2.7 \%$ & $3.0 \%$ & $3.1 \%$ & $10.5 \%$ & $58.5 \%$ \\
\hline
\end{tabular}

SB, stillbirth; TOP, termination of pregnancy.

described previously. ${ }^{8}$ Gestational age was based on the best obstetrical assessment, using information on ultrasound measures and the date of the last menstrual period. Infants were followed until death or discharge home from the hospital or into long-term care.

A standardised structured questionnaire was developed, tested and revised for use in all regions ${ }^{8}$ to collect data on all infants using common definitions agreed by the MOSAIC consortium. Data were abstracted from records in the neonatal units for babies admitted to neonatal care. For stillbirths and babies dying before admission to a neonatal unit, the questionnaires were filled in from obstetrical records. The MOSAIC questionnaire was pretested in all regions to verify its feasibility, and clarifications were made to the instrument. After data collection, the regional teams cross-checked inclusions in the study with birth registers in each maternity unit.

Data concerning the outcomes for the total cohort of deliveries from $22+0$ to $31+6$ weeks' gestational age are presented by region, by outcome for the total cohort and by three gestational age groups: 22-23 weeks, 24-27 weeks and 28-31 weeks. These groups were selected because they correspond to cut-off points used for stillbirth registration. In some countries, stillbirths are not registered below 24 weeks, while in others a 28 -week limit is used. In this study the World Health Organization (WHO) 22-week gestation cut-off was used to define a stillbirth (an infant born without signs of life). Terminations of pregnancy were categorised separately (irrespective of their outcome) into two groups: terminations for congenital anomaly and terminations for other reasons.

Rates are provided for each region concerning the proportions of very preterm infants born alive and admitted for neonatal intensive care as a proportion of all infants as well as those alive at the onset of labour and compared with the 10-region average using 95\% confidence intervals. For simplicity, the 10-regional average was not weighted to adjust for the sample sizes within the regions; differences between the weighted and nonweighted averages were slight. Analyses were carried out using STATA version 9.0 intercooled (Stata Corporation, College Station, Texas).

\section{RESULTS}

Table 1 provides information about the basic outcomes for the MOSAIC cohort by region. Wide variations were seen in the proportions of the very preterm infant outcomes across the MOSAIC regions, in particular those terminations of pregnancy for congenital anomalies, ranging from extremely rare $(0.5 \%)$ in Poland to high rates of $17.6 \%$ and $14.6 \%$ in the French and Italian regions, respectively. Information about stillborn infants is presented for antepartum stillbirths, intrapartum stillbirths and those stillbirths where the timing of death was unknown. In the Danish region $9.2 \%$ of very preterm infants were reported as stillbirths of unknown timing, explaining the extremely low proportion of reported antepartum stillbirths in this region $(1.8 \%)$. Conversely, in the Belgian region where the timing of all stillborn infants was known, the highest proportion of very preterm infants was reported as antepartum stillbirths at $17.7 \%$. The rate of labour ward deaths in this very preterm cohort varied from as little as $1.1 \%$ and $1.2 \%$ in the northern regions of the UK and Portugal, respectively, to $8.9 \%$ in the Dutch region. The proportion of this very preterm cohort who died in neonatal units was $10.5 \%$, varying from $6.8 \%$ in the French region to $25.2 \%$ in the Polish region. Overall survival rates ranged from $47.9 \%$ in the French region to $74.3 \%$ in the German region with a mean survival rate of $58.5 \%$ across all regions.

In figs $1 \mathrm{~A}-1 \mathrm{C}$, terminations of pregnancy for congenital anomaly have been excluded. These figures show the four main mortality outcomes for the cohort by gestational age group in three bands: <24 weeks, 24-27 weeks and 2831 weeks. Stillbirths of unknown timing have been aggregated with antepartum stillbirths for these figures. Although very few infants of $<24$ weeks survived neonatal care (less than $2 \%$ ), wide variations can be seen between the regions for the timing of these deaths. There were no statistically significant differences between the MOSAIC study regions in terms of mean gestational age, mean birth weight, sex and maternal age. The total cohort in the Dutch region demised prior to admission for neonatal care in direct contrast to the Polish region where almost one-half of these infants died on the neonatal unit.

Just over one-half of the MOSAIC cohort of infants from 24 to 27 weeks' gestational age died before discharge home from neonatal intensive care. This rate varied across the regions from $30.7 \%$ to $72.6 \%$. Once again large variations were seen in all categories of death. The proportion of infants who died in the intrapartum period varied from $0.9 \%$ in the German region to $12.7 \%$ in the French region; and the proportion who died on the labour ward ranged from no such deaths in the northern region of the UK to $16.1 \%$ deaths in the Dutch region.

As expected, fewer infants died in the group aged 28-31 weeks' gestation (16.5\%). Large variations were noted 

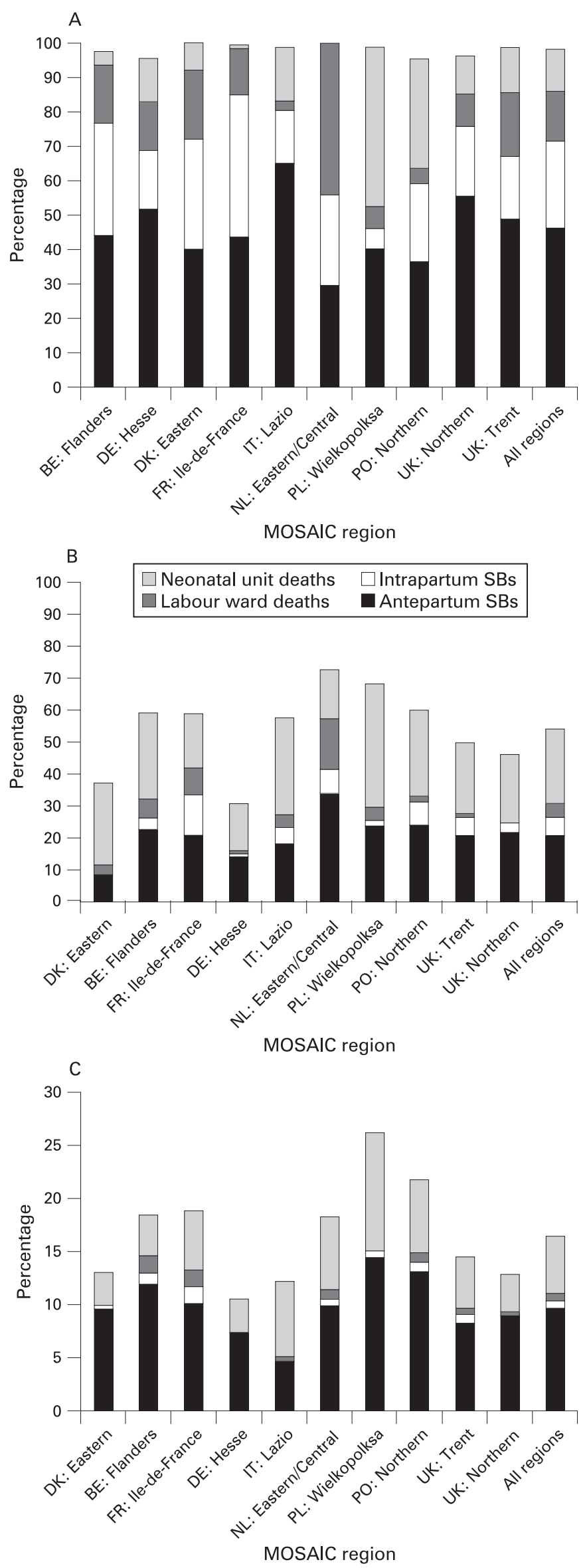

in the antepartum stillbirth group from $4.9 \%$ in the Italian region to $13.5 \%$ and $14.6 \%$ in the Portuguese and Polish regions, respectively. Similarly the Polish region had the highest proportion of deaths in the neonatal unit (11.3\%). The lowest mortality rates in the neonatal unit were from the Danish and German regions at $3.1 \%$.

Table 2 concentrates on those infants who were known to be alive at the onset of labour by the three gestational age groups. In the MOSAIC cohort of 22-23-week infants known to be alive at the onset of labour, on average just over one-half were actually born alive and of these approximately half were admitted for neonatal intensive care. Across the regions, however, statistically significant $(p<0.01)$ differences can be seen for the proportion of infants born alive from $26.5 \%$ to $89.8 \%$ for the French and Polish regions, respectively, and for neonatal admissions the proportions ranged from none in the Netherlands and $2.9 \%$ in France to $79.6 \%$ in Poland. Less variation is seen in the higher gestational age infants although the Dutch and French regions still showed a significantly lower admission rate for the 24-27-week infants and the Danish and German regions showed significantly higher admission rates for these infants compared with the regional average. Of 22-23week infants known to be alive at the onset of labour 3.1\% survived to discharge from neonatal intensive care. Survival to discharge rates for 24-27-week infants and 28-31-week infants were $58.2 \%$ and $92.4 \%$, respectively.

Figure 2 shows the variation in the mortality rate for the whole cohort by gestational age group illustrating the effect of the use of differing denominators on the mortality rate. The choice of denominator has a larger impact at lower gestational ages, for example for infants of 22-23 weeks' gestation, differences between mortality rates for those alive at the onset of labour compared with all live births, compared with all admissions for neonatal care ranged from $96.1 \%$ to $94.1 \%$ to $88.0 \%$, respectively, and at $28-31$ weeks' gestation from $7.6 \%$ to $6.9 \%$ to $6.1 \%$. Even though absolute differences are not great at higher gestational ages these different mortality rates are still statistically significant $(\mathrm{p}<0.05)$.

\section{DISCUSSION}

The aim of this project was to standardise the data collection for very preterm infants, across 10 regions in Europe, for the total cohort of $22+0$ to $31+6$-week infants. One major issue was the heterogeneity of outcomes of pregnancy for very preterm births that should be considered separately in order to develop a logical system of reporting to facilitate both intranational and international comparisons. ${ }^{9}$ For example, in the MOSAIC regions policies and practices for congenital anomalies screening and termination of pregnancies varied and some MOSAIC regions had a higher proportion of terminations of pregnancy for congenital anomalies in the very preterm births cohort: $17.6 \%$ in France and $14.7 \%$ in Italy. These different practices and their impact on the rates of termination of pregnancy have been explored elsewhere. ${ }^{10}$ We suggest that

Figure 1 (A) Mortality outcomes for the Models of OrganiSing Access to Intensive Care (MOSAIC) cohort infants of less than 24 weeks' gestational age. (B) Mortality outcomes for the MOSAIC cohort infants of between 24 and 27 weeks' gestational age. (C) Mortality outcomes for the MOSAIC cohort infants of between 28 and 31 weeks' gestational age. SB, stillbirth. 
Table 2 Outcomes of pregnancy, models of organising access to intensive care cohort by gestational age group for infants known to be alive at the onset of labour, excluding terminations of pregnancy for congenital anomalies but not for other reasons

\begin{tabular}{|c|c|c|c|c|c|}
\hline \multicolumn{2}{|c|}{ Country, region } & \multirow{2}{*}{$\begin{array}{l}\begin{array}{l}\text { Alive at onset } \\
\text { of labour }\end{array} \\
\mathrm{N}\end{array}$} & \multirow[t]{2}{*}{$\%$ Born alive $(95 \% \mathrm{Cl})$} & \multirow[t]{2}{*}{$\%$ Admitted for NIC $(95 \%$ CI) } & \multirow[t]{2}{*}{$\%$ Live discharge $(95 \% \mathrm{Cl})$} \\
\hline & $<24$ weeks' gestation & & & & \\
\hline $\mathrm{BE}$ & Flanders & 44 & $43.2(28.4$ to 59.0$)$ & 11.4 (3.8 to 24.6$)$ & $4.5(0.6$ to 15.5$)$ \\
\hline DK & Eastern & 15 & $46.7(21.3$ to 73.4$)$ & $13.3(1.7$ to 40.5$)$ & $0.0(0.0$ to 20.0$)$ \\
\hline FR & Ile-de-France & 102 & $26.5(18.2$ to 36.1$) \dagger$ & $2.9(0.6$ to 8.4$) \dagger$ & $1.0(0.0$ to 5.4$)$ \\
\hline IT & Lazio & 27 & $55.6(35.3$ to 74.5$)$ & 48.1 (28.7 to 68.1$)$ & $3.7(0.1$ to 19.0$)$ \\
\hline PO & Northern & 14 & $64.3(35.1$ to 87.2$)$ & $57.1(28.9$ to 82.3$)$ & $7.1(0.2$ to 33.9$)$ \\
\hline UK & Northern & 24 & $54.2(32.8$ to 74.5$)$ & $33.3(15.6$ to 55.3$)$ & $8.3(1.0$ to 27.0$)$ \\
\hline UK & Trent & 39 & $64.1(47.2$ to 78.8$)$ & $28.2(15.0$ to 44.9$)$ & $2.6(0.1$ to 13.5$)$ \\
\hline \multirow[t]{2}{*}{ All } & Regions & 388 & $53.1(48.0$ to 58.2$)$ & $25.8(21.6$ to 30.5$)$ & $3.1(1.6$ to 5.4$)$ \\
\hline & 24-27 weeks' gestation & & & & \\
\hline $\mathrm{BE}$ & Flanders & 184 & 95.1 (90.9 to 97.7$)$ & $87.5(81.8$ to 91.9$)$ & $52.7(45.2$ to 60.1$)$ \\
\hline NL & Eastern \& Central & 82 & $89.0(80.2$ to 94.9$)$ & $64.6(53.3$ to 74.9$) \dagger$ & 41.5 (30.7 to 52.9$)$ \\
\hline PL & Wielkopolksa/Lubuskie & 141 & $98.6(95.9 \text { to } 99.8)^{*}$ & 94.3 (89.1 to 97.5$)$ & 43.3 (35.0 to 51.9 ) \\
\hline PO & Northern & 92 & 91.3 (83.6 to 96.9 ) & 89.1 (80.9 to 94.7 ) & 53.3 (42.6 to 63.8$)$ \\
\hline UK & Northern & 131 & 96.2 (91.3 to 98.8$)$ & 96.2 (91.3 to 98.8$)$ & $68.7(60.0$ to 76.5$)$ \\
\hline UK & Trent & 223 & 92.8 (88.6 to 95.8 ) & 91.5 (87.0 to 94.8$)$ & $63.2(56.5$ to 69.6$)$ \\
\hline \multirow[t]{2}{*}{ All } & Regions & 1551 & 93.2 (91.9 to 94.4$)$ & 87.7 (86.0 to 89.3$)$ & 58.2 (55.72 to 60.7$)$ \\
\hline & 28-31 weeks' gestation & & & & \\
\hline $\mathrm{BE}$ & Flanders & 392 & 98.7 (97.1 to 99.6$)$ & $97.2(95.0$ to 98.6$)$ & 92.9 (89.8 to 95.2$)$ \\
\hline $\mathrm{DE}$ & Hesse & 416 & $100.0(99.1$ to 100.0$)$ & $100.0(99.1$ to 100.0$)$ & 96.6 (94.4 to 98.2 ) \\
\hline DK & Eastern & 236 & $99.6(97.7$ to 100.0$)$ & 99.6 (97.7 to 100.0$)$ & 96.2 (92.9 to 98.3 ) \\
\hline FR & Ile-de-France & 646 & 98.1 (96.8 to 99.0$)$ & 96.4 (94.7 to 97.7$)$ & $90.2(87.7$ to 92.4$)$ \\
\hline
\end{tabular}

*Significantly higher than the regional average.

$\dagger$ Significantly lower than the regional average.

NIC, neonatal intensive care.

terminations of pregnancy for major congenital anomalies be reported separately and excluded from comparisons of pregnancy outcomes between countries to allow for these differences. In

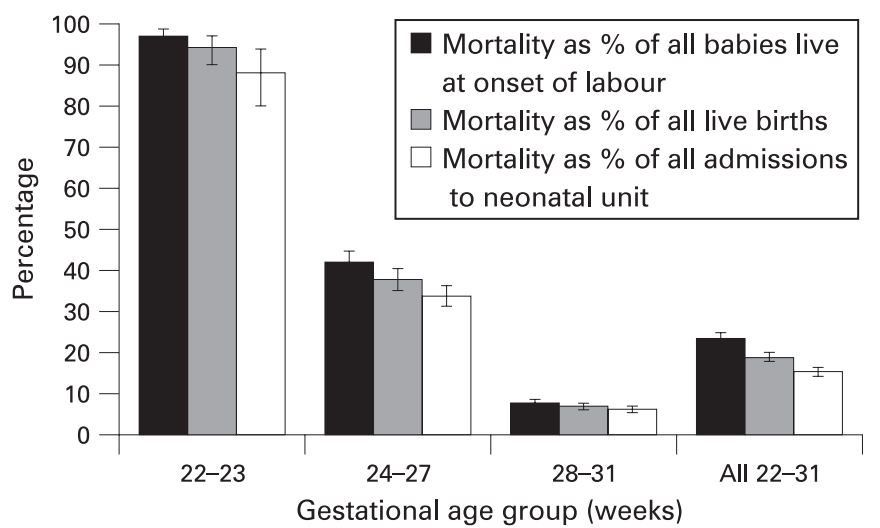

Figure 2 Variation in the mortality rate for all models of organising access to intensive care regions by gestational age group and different denominators. addition, consideration should also be given to the exclusion of lethal congenital anomalies causing stillbirth, intrapartum death or neonatal death to allow for regions where abortion is not legal.

We endeavoured to overcome viability issues in this study by collecting data from all outcomes within the defined gestational age band. This allowed us to investigate differences in the determination of the type of pregnancy outcome, in particular whether an infant was still- or live born, and if live born, whether admitted for neonatal intensive care, and to produce standardised mortality rates by gestational age. Separate analysis for gestational age bands allows for more appropriate comparisons illustrating both how the most extremely premature infant group of $<24$ weeks' gestation were classified and how they can have a large impact upon a country's mortality rates depending upon the overall denominator used for comparison.

As there were differences in definitions for birth registration between the MOSAIC regions the data collection was clearly defined by gestational age. In most regions birth registration definitions are limited to stillbirths as any live-born infant should be registered as a live birth irrespective of the gestational age and weight at delivery and, as such, mortality rates 
following a live birth should not be affected. However, these definitional differences are known to also have an effect on the registration of live births with an under-registration of live births at a boundary when a stillbirth would not require reporting, ${ }^{7}$ possibly in a paternalistic effort to relieve parents of the burden of birth registration. Conversely, a stillborn delivery that would not require reporting due to the gestational age may be over-reported as a live birth, at the parents' request, in order to require birth registration. These differences may account for some of the variation in the stillbirth rates noted in table 1 and fig $1 \mathrm{~A}$.

Whilst most MOSAIC regions used the WHO definition of the perinatal period from 22 weeks' gestation the UK only registers stillbirths from 24 weeks' gestation, Denmark (at the time of the study) only registered stillbirths from 28 weeks' gestation, Italy used a gestational age cut-off of 180 days and Germany used a lower birth weight cut-off of $500 \mathrm{~g}$ for birth registration. ${ }^{11}$ Data collection for $22-23$ weeks' gestation infants has been collected in the UK as part of the Confidential Enquiry into Stillbirths and Infant Deaths (CESDI) since 1994 and so systems were in place to capture this data. ${ }^{12}$ In the regions from Denmark, Germany and Italy, systems were set in place to ensure the collection of these data for the MOSAIC project. As such, a standardised and validated data collection was used in the MOSAIC study to ensure "like for like" comparisons although some under-reporting may still occur in these regions. Constructive efforts are being made to standardise perinatal data collection across Europe $e^{9}$ and as long as routine data include the timing of fetal death then the MOSAIC mortality definitions could be used for standardised international comparisons.

The gestational age of a live birth, in particular, those at the limits of registration of a stillborn infant, can have a direct effect upon the perceived viability of a baby which may be partially determined by unit policies, ethical decision-making and individual parental and staff attitudes which can vary widely as demonstrated by the EURONIC study. ${ }^{13}{ }^{14}$ An obvious example of policy differences in the treatment of very preterm infants from this study is shown in the data from the Dutch region in table 2 , where there were no admissions for neonatal intensive care in the $<24$-week infants and only $64.6 \%$ of infants of 24-27 weeks' gestation were admitted for neonatal intensive care compared with the regional mean admission rates of $25.8 \%$ and $87.7 \%$, respectively. Previous data from the Netherlands have also shown a very high mortality for infants of $<28$ weeks' gestational age reflecting a consensus not to actively intervene for these extremely premature infants. ${ }^{15}$

Information concerning the timing of the death of a stillborn infant is important as those known to be alive at the onset of labour (or during labour as admissions usually take place part way through the process) are those with the potential to be live born, unaffected by perception of the viability of a very preterm infant. Such data have been used to produce survival charts for very preterm babies by birth weight and gestational age in the Trent region of the UK since 1999. ${ }^{16}$ The collection of data concerning the timing of the death of a stillbirth is, however, often omitted from hospital records, as shown in the proportion of outcomes in very preterm infants recorded as stillbirths of unknown timing in the Danish region (9.2\%), Polish region $(6.0 \%)$ and northern region of the UK (4.7\%). However, discussions with the Danish team have suggested that in their cases they meant that the time of intrauterine fetal death was not known and they were all therefore antepartum stillbirths. In order to identify the "potential" live-birth cohort and allow direct comparisons of mortality rates for these infants this information needs to be recorded systematically in the medical records. To overcome this problem we grouped stillbirths of unknown timing with antepartum stillbirths as it was assumed that the reporting of intrapartum stillbirths was more rigorous and therefore allowed us to identify our "potential" live-birth cohort. This analysis provided some insight into the decisionmaking processes in each region possibly based on policies determined by the sickness of the infants and the organisation of care within each gestational age band.

The provision of detailed information about all outcomes from very preterm delivery by gestational age band facilitates the interpretation of data and enables epidemiologists and clinicians to determine why particular outcomes are higher for their populations. Local issues such as ascertainment, access to facilities and quality of labour ward services can then be investigated to provide the complete picture. Adjustment for the case mix of infants admitted for neonatal intensive care clearly provides an additional level of information about the quality of the service ${ }^{17} 18$ but this is the next level of analysis.

This paper has shown differences in mortality rates for very preterm deliveries across the MOSAIC regions and addresses the need for us to be able to directly compare international statistics for mortality in very preterm babies in a routine and standardised manner. We have highlighted the large policy, ethical and cultural differences that appear to be inherent in such data which may account for some of the variation seen. The first step in trying to investigate differences in practice and access is to ensure that data collection is standardised as in the MOSAIC project. We believe that the standard point of comparison should be using all those infants alive at the onset of labour as the denominator for comparisons of mortality rates for very preterm infants analysing the cohort by gestational age band. Exclusion of all lethally malformed fetuses and neonates should also be considered.

Acknowledgements: The MOSAIC Research Group: Flanders, Belgium (E Martens, G Martens, A Bekaert, P Van Reempts); Eastern Denmark, Denmark (K Boerch, T Weber, B Peitersen); Ile-de-France, France (G Bréart, J L Chabernaud, D Delmas, E Papiernik): Hesse, Germany (L Gortner, W Künzel, R Maier, B Misselwitz,

S Schmidt); Lazio, Italy (R Agostino, D Di Lallo, R Paesano); Eastern \& Central Netherlands (L den Ouden, L Kollée, G Visser, J Gerrits, R de Heus); Northern Wielkopolska \& Lubuskie, Poland (G Breborowicz, J Gadzinowski, J Mazela); Northern Region, Portugal (H Barros, I Campos, M Carrapato); Trent Region, UK (E Draper, D Field, J Konje); Northern Region, UK (A Fenton, D Milligan, S Sturgiss); INSERM U149, Paris (G Bréart, B Blondel, H Pilkington, J Zeitlin); external contributors (M Cuttini, S Petrou). Steering committee (E Papiernik, project leader, J Zeitlin, research coordinator, G Bréart, E S Draper, L Kollée).

Funding: This project was partially funded by a grant from the European Commission Research Directorate (QLG4-CT-2001-01907) and coordinated by Assitance PubliqueHôpitaux de Paris. The MOSAIC research group maintained complete independence from the funding body in relation to the research process and reporting of results. The authors would like to acknowledge the assistance of the personnel in the maternity and neonatal units in the regions participating in the MOSAIC project.

Competing interests: None.

Ethics approval: Ethics approval was sought for the collection of these data as required in each of the regions.

Contributors: The conception and design of article were developed by the listed authors. Analysis and interpretation of the data were carried out by ESD and JZ. ESD wrote the first draft of the paper and all authors participated in revisions and approved the final manuscript. ESD is the guarantor.

\section{REFERENCES}

1. Garne E. Perinatal mortality rates can no longer be used for comparing quality of perinatal health between countries. Paediatr Perinat Epidemiol 2001;15:315-16.

2. Kramer MS, Platt RW, Yang $\mathrm{H}$, et al. Registration artifacts in international comparisons of infant mortality. Paediatr Perinat Epidemiol 2002;16:16-22.

3. Richardus JH, Graafmans WC, Verloove-Vanhorick SP, et al. Differences in perinatal mortality and sub-optimal care between 10 European regions: results of an international audit. BJOG 2003;110:97-105. 
4. Field D, Petersen $\mathrm{S}$, Clarke $\mathrm{M}$, et al. Extreme prematurity in the UK and Denmark: population differences in viability. Arch Dis Child 2002;87:F172-5.

5. Draper ES, Zeitlin J, Field DJ, et al. Mortality patterns of very preterm babies: a comparative analysis of two European regions in France and England. Arch Dis Child Fetal Neonatal Ed 2007;92:F356-60.

6. Buitendijk S, Zeitlin J, Cuttini M, et al. Indicators of fetal and infant health outcomes. Eur J Obstet Gynaecol Reprod Biol 2003:111:S66-77.

7. Kramer MS, Platt RW, Yang H, et al. Registration artifacts in international comparisons of infant mortality. Paediatr Perinat Epidemiol 2002;16:16-22.

8. Zeitlin J, Draper ES, Kollee L, et al. Differences in rates and short term outcome of live births before 32 weeks of gestation in Europe in 2003: results from the MOSAIC cohort. Pediatrics 2008:121:e936-44.

9. Zeitlin J, Wildman K, Breart G, et al. PERISTAT Indicators for monitoring and evaluating perinatal health in Europe. Eur J Public Health 2003;13(Suppl 3):29-37.

10. Papiernik E, Zeitlin J, Delmas D, et al. Terminations of pregnancy among very preterm births and its impact on very preterm mortality: results from ten European population-based cohorts in the MOSAIC study. BJOG 2008;115:361-8.

11. MacFarlane A, Gissler M, Bolumar F, et al. The availability of perinatal health indicators in Europe. Eur J Obstet Gynaecol Reprod Biol 2003;111(Suppl 1):S15-32.

12. Clarke M, Draper E, James D, et al. Confidential Enquiry into Stillbirths and Deaths in Infancy (CESDI) 1997. Trent Institute for Health Services Research: Trent Infant Mortality and Morbidity Studies, 1998

13. McHaffie HE, Cuttini M, Brolz-Voit G, et al. Witholding/withdrawing treatment from neonates: legislation and official guidelines across Europe. J Med Ethics 1999;25:440-6.

14. Cuttini M, Nadai M, Kaminski M, et al. End-of-life decisions in neonatal intensive care: physicians' self-reported practices in seven European countries. EURONIC Study Group. Lancet 2000;355:2112-18

15. van der Heide $\mathbf{A}$, van der Maas PJ, van der Wal G, et al. Medical end-of-life decisions made for neonates and infants in the Netherlands. Lancet 1997:350:251-5.

16. Draper ES, Manktelow B, Field DJ, et al. Prediction of survival for preterm births by weight and gestational age: retrospective population based study. BMJ 1999:319:1093-7.

17. The International Neonatal Network. The CRIB (clinical risk index for babies) score: a tool for assessing initial neonatal risk and comparing performance of neonatal intensive care hospitals. Lancet 1993;342:192-8.

18. Parry GJ, Gould CR, McCabe CJ, et al. Annual league tables of mortality in neonatal units: Iongitudinal study. International Neonatal Network and the Scottish Neonatal Consultants and Nurses Collaborative Study Group. BMJ 1998;316:1931-5.

\section{Images in neonatal medicine}

\section{Large calcified intra-abdominal mass in a newborn}

A 33-week infant was born to a gravida eight mother with a poor obstetric history. A late second trimester scan had shown a large intra-abdominal cyst in the fetus and polyhydramnios. The mother went into spontaneous labour at 33 weeks and a male baby was delivered by caesarean section. Soon after birth the infant was noted to have abdominal distension and bilious aspirates. A radiograph of the abdomen revealed a calcified mass suggestive of meconium pseudocyst (fig 1). Laparotomy on the second postnatal day revealed a meconium pseudocyst located between the liver, stomach and transverse colon with many adhesions. There were two perforations from the terminal ileum into the pseudocyst approximately $10 \mathrm{~cm}$ from the ileo-caecal valve. The cyst was excised and a split ileostomy was performed. The ileostomy was reversed and an end to end anastamosis performed a month later. The baby recovered well post-operatively and on follow-up was thriving well.

Meconium peritonitis in a fetus is a potentially fatal condition occurring as a result of antenatal perforation of the bowel. ${ }^{1}$ Bowel perforation is usually secondary to intestinal obstruction from meconium ileus, microcolon, intussusception, intestinal atresia and volvulus. ${ }^{2}{ }^{3}$ Some cases may be idiopathic. It can lead to extensive generalised peritonitis (type I), meconium pseudocyst formation (type II) or complete prenatal restoration with residual intraabdominal calcifications (type III). ${ }^{4}$ The formation of a pseudocyst represents an attempted intra-abdominal healing process to confine the perforation. The cyst may communicate openly with a segment of adherent bowel. ${ }^{14}$ Antenatally, the cysts can be detected by ultrasonography but may not be apparent until the last trimester of pregnancy. ${ }^{2}{ }^{4}$ Calcification may be present in only $25 \%$ of cases. ${ }^{5}$

\section{N Simmons, ${ }^{1}$ N J Shaw, ${ }^{1}$ G Mann, ${ }^{2}$ C P H Ibrahim ${ }^{1}$}

${ }^{1}$ Neonatal Unit, Liverpool Women's Hospital NHS Foundation Trust, Liverpool, UK;

${ }^{2}$ Department of Radiology, Royal Liverpool Children's NHS Trust, Adler Hey, Liverpool, UK

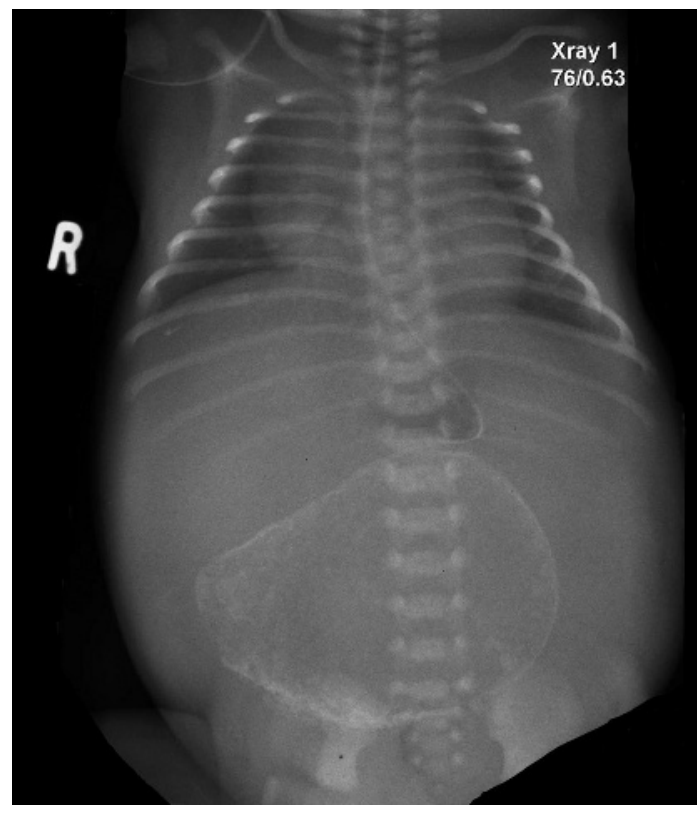

Figure 1 Antero-posterior radiograph of the abdomen showing a centrally placed ovoid mass lesion with punctate peripheral calcification. A linear area of calcification is seen under the diaphragm in the T8/T9 intercostal space on the right.

Correspondence to: Professor N J Shaw, Neonatal Unit, Liverpool Women's Hospital NHS Foundation Trust, Liverpool UK L8 7SS, UK; Ben.Shaw@lwh.nhs.uk

Competing interests: None.

Patient consent: Parental consent obtained.

Arch Dis Child Fetal Neonatal Ed 2009;94:F163. doi:10.1136/adc.2008.154252

\section{REFERENCES}

1. Khong PL, Cheung SC, Leong LL, et al. Ultrasonography of intra-abdominal cystic lesions in the newborn. Clin Radiol 2003;58:449-54.

2. Simonovský V, Lisý J. Meconium pseudocyst secondary to ileal atresia complicated by volvulus: antenatal MR demonstration. Pediatr Radiol 2007;37:305-9.

3. Mercado MG, Bulas DI, Chandra R. Prenatal diagnosis and management of congenital volvulus. Pediatr Radiol 1993;23:601-2

4. Eckoldt F, Heling KS, Woderich R, et al. Meconium peritonitis and pseudo-cyst formation: prenatal diagnosis and post-natal course. Prenat Diagn 2003;23:904-8.

5. Kamata S, Nose K, Ishikawa $\mathrm{S}$, et al. Meconium peritonitis in utero. Pediatr Surg Int 2000:16:377-9. 